\title{
Sex differences in motion perception of Adler's six great ideas and their opposites
}

\author{
RICHARD D. WALK and JACQUELINE M. F. SAMUEL \\ George Washington University, Washington, D.C.
}

\begin{abstract}
A mime presented on videotape Adler's six great ideas of truth, goodness, beauty, liberty, equality, and justice; their opposites; and the transitions from the positive or "good" concepts to their opposites. Using Johansson's (1973) technique, the performer's 12 joints were marked with points of light. Overall, the viewers had marginal success in identifying the concepts, but females were much more successful than males in identifying the "bad" ones of evil, slavery, falsehood, and ugliness, averaging $62 \%$ correct to the males' $23 \%$. The results agree with Hall's (1984) discussion of sex differences in the interpretation of nonverbal behavior.
\end{abstract}

Adler (1981) posited six great ideas that have influenced civilization. The ideas are truth, goodness, beauty, liberty, equality, and justice. We wondered whether such ideas might be understood in abstract form through human movement.

We used a technique, pioneered by Johansson (1973), in which points of light are attached to joints of the body. Without movement, the pattern of lights has no particular meaning; with movement, the lights are immediately seen as a human figure in motion (Johansson, 1973). Representative prior research has shown that human infants prefer to look at light patterns from the human body over similar patterns of light with no human reference (Fox \& McDaniel, 1982), that male and female walking patterns can be distinguished (Cutting \& Proffitt, 1981), that people can recognize their friends by their gaits (Cutting \& Kozlowski, 1977), and that the body can project distinct emotions and different dance configurations (Walk \& Homan, 1984).

In the present experiment, a mime presented on a videotape her concept of the six great ideas and their opposites. First, the "good" concepts (beauty, equality, goodness, justice, liberty, and truth) were presented. These were followed by their respective opposites (ugliness, inequality, evil, injustice, slavery, and falsehood). Finally, the good concepts were turned into the "bad"' ones (beauty to ugliness, equality to inequality, goodness to evil, justice to injustice, liberty to slavery, and truth to falsehood). A different random order was used for each presentation.

\section{METHOD}

\section{Subjects}

The subjects were 32 students from two laboratory sections in an undergraduate course in experimental psychology. Eleven were males and 21 were females.

This experiment was supported in part by National Institutes of Health Biomedical Research Support Grant 2-S0-RR07019-14 to George Washington University. Requests for reprints should be sent to Richard D. Walk, Department of Psychology, George Washington University, Washington, DC 20052.

\section{Materials}

A videotape was made, showing 18 sequences of behavior. The performer was videotaped wearing a black leotard, with black stockings on her feet and hands and a black pillowcase over her head. Cotton makeup balls were attached with masking tape to the performer's wrists, elbows, shoulders, hips, knees, and ankles. The performer was videotaped against a black background (black cloth taped to the wall and also placed on the floor). The video equipment was a SONY HVC-2800 Trinicon video camera that used Beta tape. When the contrast on the television monitor was turned down, the observers could see only 12 points of light moving on the television screen. Each "concept" or sequence of behavior lasted about 5 to $15 \mathrm{sec}$, followed by a gap to allow the subjects time to write their responses. The tape lasted a total of $6 \mathrm{~min}$ $8 \mathrm{sec}$, beginning at 3 on the tape counter and ending at 30 .

The light sequences are difficult to describe. They must be seen. Tables 1 and 2 are lists of movements that the performer and a viewer, respectively, imagined would help an observer interpret the light movements as representing the concepts. Table 3 lists some general characteristics of positive and negative concepts from the performer's point of view, and Table 4 is a description of the movements of the figure from the point of view of a viewer. Tables 1-3 reflect the viewpoint of the performer, (J.M.F.S., female, a coauthor with 2 years experience as a mime and a degree in experimental psychology); Table 4 represents the viewpoint of the viewer (R.D.W., male, a coauthor who is an experimental and developmental psychologist). The image on the videotape consists of 12 points of light that move in an organized way, which the observer interprets as a figure in motion. No light is reflected from a point or points on the head, yet we refer to the performer as "looking into the future." In Johansson's technique the observer imagines a head that is not there, an example of meaning inferred from the "sound of silence" in perception (Walk, 1984). Anyone interested in this research can send us a blank Beta videotape for a copy of our videotape, Adler's Six Great Ideas and Their Opposites, in Mime, by R. D. Walk and J. M. F. Samuel (1986).

The order in which the concepts appear on the videotape and were shown to the subjects is presented below. The time of each sequence, in seconds, is shown in parentheses after the concept. A 10-sec gap followed each sequence, and a 30-sec gap occurred between each type of concept, good concepts first, then bad concepts, then transitions from good concepts to bad.

1. justice (8.5), truth (6.6), equality (7.5), beauty (7.1), liberty (4.0), and goodness (8.8);

2. evil (6.0), injustice (8.7), slavery (8.6), falsehood (7.7), inequality (8.1), and ugliness (9.3);

3. equal to unequal (9.7), liberty to slavery (11.1), good to evil (11.0), justice to injustice (15.0), truth to falsehood (11.4), and beautiful to ugly (11.6).

\section{Procedure}

The subjects were handed a response sheet with the following words: 
Table 1

The Performer's Description of Movements Representing Positive Concepts, Negative Concepts, and Transitions Between Them

Positive Concepts

Justice

Truth

Equality

Beauty

Liberty

Goodness

Evil

open, even, rigid, honest.

open, simple, smooth, relaxed

simple, symmetric, smooth, relaxed, slow, deliberate

smooth, curves, unusual pattern, spacious variety in openness and closedness

free, unrestrained movement, open, relaxed, elation, faster pace, projected outward smooth, soft, protective, gentle, rounded, projected inward

\section{Negative Concepts}

erratic, devious, turned away, cut off from environment, contracted, oblique movements

Injustice

Slavery

Falsehood

Inequality

Ugliness

Equal to Unequal

Liberty to Slavery

Good to Evil

Justice to Injustice

Truth to Falsehood

Beautiful to Ugly

rigid, preference for one side, oblique, unbalanced

powerless, at the mercy of outside power, pulled by external force, oblique, tense

erratic, unpredictable, angular, pulled in or contracted, hesitant, uneven, asymmetrical static, asymmetry, closed to environment weak, asymmetrical, shapeless, unclear, erratic, like jelly

\section{Transitions}

simple symmetry to asymmetry

source of power moving from inside to outside of body, activity level diminishes open, rounded movements changing to jagged, closed, oppressive movements

simple symmetry sliding into powerless disequilibrium

open, upward movement changes to closed, downward position

simple, smooth, open, slow movements changed to jagged, contracted, faster movements

You will be shown abstract concepts represented in points of light as expressed by the body movement of a mime. You will be shown the concepts shown to the right (in alphabetical order), and your task is to write down the concept that you think is expressed each time. You will note that the first showing is of "good" concepts, the second one of "bad" concepts, and the third one of the "good" concepts turning into "bad" ones.

The response sheet was divided into three groups of six trials, each numbered from 1 to 6 . The groups were labeled "first showing," "second showing," and "third showing." Each group of concepts was in alphabetical order. To ensure that the subjects understood their task, the experimenter read the instructions aloud while the subjects followed the script. An informal question-and-answer period followed. The subjects were asked to write down a guess on every trial, even if they were not sure what to write.

\section{RESULTS}

In discriminating the concepts, $72 \%$ of subjects $(54 \%$ of the males and $81 \%$ of the females) were above the chance level of 3 correct responses of 18 . For the entire sample, this is highly significant $[t(31)=4.284, p<$ $.001]$, but when broken down by gender, significant only for females $[t(20)=4.488, p<.001]$, not for males $[t(10)=1.218$, n.s. $]$.

The subjects were most successful in identifying the bad concepts (34\% overall), followed by the transitions from good to bad (29\% correct). They were least successful with the good concepts ( $20 \%$ correct). Chance, of course, is $17 \%$ correct. A repeated measures analysis of variance revealed a significant difference between subjects' recognition of concepts $[F(2,62)=4.69, p<.02]$. The Newman-Keuls test showed that the only significance between subjects' recognition of concepts was that between good and bad concepts $(p<.01)$. These results are shown in Table 5.

Table 2

The Viewer's Description of Movements Representing Positive Concepts, Negative Concepts, and Transitions Between Them

\section{Positive}

Justice

Truth

Equality

Beauty

Liberty

Goodness

Evil

Injustice

Slavery

Falsehood

Inequality

Ugliness

Equal to Unequal

Liberty to Slavery

Good to Evil

Justice to Injustice

Truth to Falsehood

Beautiful to Ugly symmetry coming into equilibrium, balancing out

dancing movement, relaxed and open, coming to rest

simple, symmetrical movement, upward and then down, like taking a deep breath, controlled

many gentle curves ending in a protective curved position, upward open, then down jumping, happy, subdued at end

beginning ominous, becoming softer and friendlier, protective in the end, rounded movements

\section{Negative}

devious, asymmetrical, jagged movements, conniving

movement pattern out of balance on top part, base is steady

frightened, being pulled against one's will, weak

playful, nasty, erratic, frivolous loses balance at end

being displeased, hiding, turning into oneself, indecisive

\section{Transitions}

inward symmetrical movement gently changes to asymmetrical pattern

happy, fast, open movements change to hesitant, dependent, weak poses smooth, round movements change to jagged, teasing, irritating movements visual equilibrium gets established and slowly slides to permanent imbalance, weak being in awe and open changes to being frightened and closed. Upward to downward, simple to complicated

gentle human movements to small, tight, mechanical movements downward. Gentleness to unpredictable jaggedness quiet asymmetrical pattern comes to rest, 
Table 3

General Movement Characteristics of Positive and Negative Concepts (Performer's Point of View)

\begin{tabular}{ll}
\hline \multicolumn{1}{c}{ Positive Concepts } & \multicolumn{1}{c}{ Negative Concepts } \\
\hline $\begin{array}{l}\text { Horizontal, vertical } \\
\text { Symmetry }\end{array}$ & Oblique \\
$\begin{array}{l}\text { Incorporates outside space, } \\
\text { open to environment }\end{array}$ & $\begin{array}{l}\text { Asymmetry } \\
\text { Retracting from space around, } \\
\text { closed to environment and others } \\
\text { Slower }\end{array}$ \\
Organized & Faster \\
Smooth & Erratic \\
Relaxed & Jagged \\
Round & Tense \\
Directed upward & Angular \\
Control & Directed downward \\
Upward, out & Out of control \\
\hline
\end{tabular}

Table 4

Outside, Objective View of Performer's Portrayal of Positive and Negative Concepts

\section{Positive Concepts}

Justice arms extended straight out to side, performer slightly squatting, knees symmetrically flexed, horizontal arms tilt up and down, end horizontal, balanced

Truth performer first makes circular motion with both arms and hands, body straight, erect, "looking to future," right arm large circular motion, slight crouch while looking into distance, right arm horizontal, left at $45^{\circ}$ upward

Equality stands straight, arms out to side and straight up over head, arms down, elbows forward toward camera, stops, compact frontal view of body

Beauty symmetrical movements, ends with body inclined to left, kneeling slightly, with arms up

Liberty leaps up and down, symmetrically facing forward, ends with inverted " $V$ " shape

Goodness faced foward, body does irregular movement, arms slant out, finished tucked near waist, much like

"beauty" except more rotational movement of hands

\section{Negative Concepts}

Evil faced foward, body then makes irregular twisting movements, ends in left oblique

Injustice like depiction of "justice" except that outstretched arms aslant or unbalanced at end

Slavery body weaves back and forth, crouched, arms outstretched as if being pulled by rope (chains?) toward left

Falsehood faced foward, body tight and close in, close irregular movements up and down with knees, body to left but shoulders and head forward

Inequality faced foward, erect, close in up and down movements of hands and feet, ends with one foot up, one arm higher than the other

Ugliness body asymmetrical, leans to left, sinuous, snakelike movements as body slowly twists downward, ends in compact crouch, head down

The individual concepts and the subjects' guesses are shown in Table 6 . The concepts identified correctly most often were slavery $(72 \%)$, the transition from liberty to slavery (63\%), beauty (53\%), and evil (53\%). All justiceinjustice presentations were confused with equalityinequality. Justice was misidentified as equality by $81 \%$ of the subjects, injustice called inequality by $91 \%$ of the subjects, and the transition from justice to injustice called the transition from equality to inequality by $84 \%$ of the subjects. Of course, for this type of experiment, in which abstract meanings of nonverbal behavior are explored, one can argue that the subjects were "correct" and we were not.

Overall, the females averaged $32 \%$ correct and the males $21 \%$ (chance $=17 \%$ correct). The overall malefemale difference approaches, but does not quite reach, significance $[t(30)=1.932, p<.10]$. In identifying the bad concepts, however, the females were superior to the males, averaging $43 \%$ correct to $17 \%$, meaning that the males were at a chance level. This difference is highly significant $[t(30)=3.481, p<.01]$. If one eliminates injustice and inequality, confused by almost all subjects, then females averaged $62 \%$ on the remaining four bad concepts of evil, slavery, falsehood, and ugliness, whereas males averaged $23 \%$ correct. This is a very significant sex difference $[t(30)=4.272, p<.001]$. The performer is female, and our research seems to have uncovered a secret body languge understood by females and not by males.

\section{DISCUSSION}

Our attempt to find body movements expressive of the abstract concepts of Adler's six great ideas of truth, goodness, beauty, liberty, equality, and justice had limited success. If one changes the meaning of our depiction of justice to equality and retains the interpretation of beauty as a concept, then we have two possible "great idea" concepts expressed as body movement. The depictions of the negative opposites of some of Adler's great ideas-falsehood, evil, ugliness, and slavery-were identified more successfully, but only among females. By reinterpreting the meaning of inequality as injustice, five of our six depictions of negative concepts may be interpretable by some subjects. This is not the way the experiment was planned, but we have shown that bodily movement can convey some abstract concepts.

The most impressive finding of the experiment was the sex difference: women were far superior to men in decoding the negative concepts of falsehood, evil, ugliness, and slavery. Hall's (1984) review of sex differences in the decoding of nonverbal behavior generally shows that women are superior to men. Hall's review also shows that women are superior to men in decoding negative concepts, so our results agree with hers.

Our studies also indicate the importance of the performer. An earlier study of ours (Walk \& Homan, 1984) found that women are superior to men in decoding bodily movements expressive of emotion and dance,

Table 5

Discrimination of Concepts by Type of Concept and Sex Differences

Type of Concept

\begin{tabular}{lcccc}
\hline & \multicolumn{3}{c}{ Type of Concept } & \\
\cline { 2 - 3 } & Good & Bad & Good to Bad & Total \\
\hline \multicolumn{4}{c}{ Total Sample } \\
Mean correct & 1.22 & 2.06 & 1.75 & 5.03 \\
Percent correct & $20 \%$ & $34 \%$ & $29 \%$ & $28 \%$ \\
& \multicolumn{4}{c}{ Males } \\
Mean correct & 1.00 & 1.00 & 1.82 & 3.82 \\
Percent correct & $17 \%$ & $17 \%$ & $30 \%$ & $21 \%$ \\
& \multicolumn{4}{c}{ Females } \\
Mean correct & 1.33 & 2.57 & 1.71 & 5.67 \\
Percent correct & $22 \%$ & $43 \%$ & $29 \%$ & $32 \%$ \\
\hline
\end{tabular}


Table 6

Six Great Ideas in Mime: The Relation Between the Stimulus Presented and the Subjects' Guesses

\begin{tabular}{|c|c|c|c|c|c|c|}
\hline \multirow[b]{2}{*}{ Presented } & \multicolumn{6}{|c|}{ Guessed } \\
\hline & Beauty & Equality & Goodness & Justice & Liberty & Truth \\
\hline Beauty & $53 \%$ & - & $3 \%$ & $6 \%$ & $19 \%$ & $19 \%$ \\
\hline Equality & $6 \%$ & $6 \%$ & $31 \%$ & $28 \%$ & $6 \%$ & $22 \%$ \\
\hline Goodness & $16 \%$ & $3 \%$ & $16 \%$ & $22 \%$ & $22 \%$ & $22 \%$ \\
\hline Justice & - & $81 \%$ & $3 \%$ & $13 \%$ & $3 \%$ & - \\
\hline Liberty & $13 \%$ & $9 \%$ & $38 \%$ & $13 \%$ & $13 \%$ & $16 \%$ \\
\hline \multirow[t]{2}{*}{ Truth } & $13 \%$ & - & $6 \%$ & $16 \%$ & $41 \%$ & $22 \%$ \\
\hline & Ugliness & Inequality & Evil & Injustice & Slavery & Falsehood \\
\hline Ugliness & $38 \%$ & - & $13 \%$ & $16 \%$ & $6 \%$ & $28 \%$ \\
\hline Inequality & $34 \%$ & $6 \%$ & $9 \%$ & $16 \%$ & $9 \%$ & $25 \%$ \\
\hline Evil & $3 \%$ & - & $53 \%$ & $16 \%$ & $16 \%$ & $9 \%$ \\
\hline Injustice & $3 \%$ & $91 \%$ & - & $6 \%$ & - & - \\
\hline Slavery & $3 \%$ & $6 \%$ & - & $13 \%$ & $72 \%$ & $6 \%$ \\
\hline \multirow[t]{2}{*}{ Falsehood } & $16 \%$ & - & $22 \%$ & $28 \%$ & $3 \%$ & $31 \%$ \\
\hline & $\begin{array}{l}\text { Beautiful } \\
\text { to Ugly }\end{array}$ & $\begin{array}{l}\text { Equal to } \\
\text { Inequal }\end{array}$ & $\begin{array}{l}\text { Good } \\
\text { to Evil }\end{array}$ & $\begin{array}{l}\text { Just to } \\
\text { Injust }\end{array}$ & $\begin{array}{c}\text { Liberty to } \\
\text { Slavery }\end{array}$ & $\begin{array}{l}\text { Truth to } \\
\text { Falsehood }\end{array}$ \\
\hline Beautiful to Ugly & $28 \%$ & $13 \%$ & $25 \%$ & $9 \%$ & - & $25 \%$ \\
\hline Equal to Inequal & $25 \%$ & $3 \%$ & $6 \%$ & $31 \%$ & $9 \%$ & $22 \%$ \\
\hline Good to Evil & $28 \%$ & - & $34 \%$ & $6 \%$ & $13 \%$ & $16 \%$ \\
\hline Just to Injust & - & $84 \%$ & $3 \%$ & $9 \%$ & $3 \%$ & - \\
\hline Liberty to Slavery & $3 \%$ & - & $13 \%$ & $19 \%$ & $63 \%$ & $3 \%$ \\
\hline Truth to Falsehood & $16 \%$ & $3 \%$ & $9 \%$ & $19 \%$ & $13 \%$ & $38 \%$ \\
\hline
\end{tabular}

Note-Wording of transitions has been shortened.

but the difference in that study, although statistically significant, was not large $(68 \%$ correct for women and $58 \%$ for men). Walk and Homan's study had two performers, both women, and the present study used the mime who interpreted emotions in Walk and Homan's study. An unpublished study by Walk and Walters (1985) had several different performers, three females and one male, interpreting the emotions of anger, disgust, fear, happiness, sadness, and surprise, and the only significant sex difference was that movements by the male performer were identified correctly $82 \%$ of the time by male subjects and $61 \%$ of the time by female subjects. Thus, we agree with LaFrance (1986) that the sex of the performer may be important.

Our experiment reports probably as large a difference between the sexes in interpreting nonverbal behavior as any previously found. Tables 1-4, perhaps used in conjunction with our videotape, may lead to research to understand the stimulus basis for the difference. Our hope is that a difference as large as the one we have reported will lead to further research to understand sex differences in decoding nonverbal behavior.

\section{REFERENCES}

Adler, M. J. (1981). Six great ideas. New York: Macmillan.

Cutring, J. E., \& KozlowsKI, L. T. (1977). Recognizing friends by their walk: Gait perception without familiarity cues. Bulletin of the Psychonomic Society, 9, 353-356.
Cutting, J. E., \& Proffitr, D. R. (1981). Gait perception as an example of how we perceive events. In R. D. Walk \& H. L. Pick, Jr. (Eds.), Intersensory perception and sensory integration (pp. 249-273). New York: Plenum Press.

Fox, R., \& McDaniel, C. (1982). The perception of biological motion by human infants. Science, 218, 486-487.

Hall, J. A. (1984). Nonverbal sex differences: Communicative accuracy and expressive style. Baltimore: Johns Hopkins University Press.

Johansson, G. (1973). Visual perception of biological motion and a model for its analysis. Perception \& Psychophysics, 14, 201-211.

LAFrance, M. (1986). Review of J. A. Hall, Nonverbal sex differences: Communication accuracy and expressive style. Contemporary Psychology, 31, 793-794.

WALK, R. D. (1984). Event perception, perceptual organization and emotion. In W. R. Crozier \& A. J. Chapman (Eds.), Cognitive processes in the perception of art (pp. 211-221). Amsterdam: Elsevier. WALK, R. D., \& HomaN, C. P. (1984). Emotion and dance in dynamic light displays. Bulletin of the Psychonomic Society, 22, 437-440.

WALK, R. D., \& W ALTERS, K. L. (1985, November). Event perception studies of the bodily expression of emotion. Paper presented at the meeting of the Psychonomic Society, Boston, MA.

(Manuscript received for publication October 8, 1987.) 